\title{
OS ATRAVESSAMENTOS DA SAÚDE NA EDUCAÇÃO E OS EFEITOS DA GOVERNAMENTALIDADE
}

\author{
Roberta de Mendonça Porto \\ Luiz, Antonio Saléh Amado
}

\section{Resumo}

Este artigo objetiva discutir os efeitos da implementação da Política Nacional de Educação Especial de 2008 no município de Linhares, ES, a partir do encontro entre educação e saúde. Os dados dessa pesquisa referem-se ao ano de 2010 e foram analisados sob as lentes da Análise Institucional. Com base nesses pressupostos, nos voltamos para a nova organização da rede, após a implementação da PNEE 2008, que estabeleceu uma parceria entre saúde e educação. A partir disso, observou-se o aumento da demanda de avaliação das dificuldades de aprendizagem e de problemas comportamentais dos estudantes por parte das escolas e de seus profissionais. Este efeito emergiu neste trabalho como um analisador histórico: Aumento da demanda por avaliação, apontando para como tem se constituído a relação entre saúde e educação no âmbito da escola e abrindo espaços para novas organizações desta relação. Questões até então corriqueiras no cotidiano escolar passaram a ser consideradas disfunções neuropsicológicas dos estudantes, demandando, assim, a avaliação de uma equipe de saúde. Diante disso, a equipe de trabalho elaborou uma série de estratégias que pudessem minimizar o processo de medicalização escolar que estava se instituindo naquela rede. Essas estratégias aproximaram os profissionais da saúde e da educação, permitindo que os profissionais da escola colocassem suas práticas em análise e produzissem mudanças nas relações e práticas da escola.

Palavras-chave: PNEE 2008; medicalização escolar; saúde e educação.

\section{THE ALLIANCE BETWEEN HEALTH AND EDUCATION AND THE EFFECTS OF GOVERNMENTALITY}

\begin{abstract}
The article analyzes the implementation effects of the 2008 National Policy on Special Education (PNEE) in pedagogical practices, in the city of Linhares, ES, based on the meeting between education and health. The analyzes are based on the Institutional Analysis. The survey data is from 2010, when a team of five health professionals started to implement PNEE. The education network's new organization prioritized intersectoral articulation, bringing health and education professionals together. At this time, the demands for evaluation of students' behavior and learning difficulties was increased. The transformation of everyday issues in school life into potential neuropsychological dysfunctions can be considered one of the causes. The increase of the demand for evaluation emerged as a historical analyzer, pointing to how the relationship between health and education has been formed within the school and opening spaces for new organizations of this relationship. The work team then elaborated strategies that minimized the school medicalization process that was instituted in that network, allowing the health and education professionals to analyze their implications with the present institutions and allowing to analyse their practices, thus producing the necessary changes.
\end{abstract}

Keywords: national policy on special education; school medicalization; education and health. 


\section{LA ALIANZA ENTRE LA SALUD Y LA EDUCACIÓN Y LOS EFECTOS DE LA GOBERNAMENTALIDAD}

\section{Resumen}

Este artículo objetiva analizar los efectos de la implementación de la Política Nacional de Educación Especial de 2008 en las prácticas pedagógicas, en el municipio de Linhares, ES, a partir del encuentro entre educación y salud. Los datos de la pesquisa se refieren al año 2010. Los análisis realizados se apoyan en el Análisis Institucional. En base a estos supuestos, nuestros análisis se volvieron a la nueva organización de la red, tras la implementación de la PNEE 2008, que priorizó la articulación entre profesionales de salud y educación. A partir de eso, fue posible observar el aumento de la demanda de evaluación del comportamiento y de las dificultades de aprendizaje de los estudiantes por parte de las escuelas y sus profesionales, fruto de la transformación de cuestiones antes corrientes en el cotidiano escolar en potenciales disfunciones neuropsicológicas. Este efecto, Aumento de la demanda por evaluación, emergió como un analizador histórico, señalando cómo se ha constituido la relación entre salud y educación en el ámbito escolar y abriendo espacios para nuevas organizaciones de esta relación. El equipo de trabajo elaboró entonces una serie de estrategias que minimizar el proceso de medicalización escolar que se instituía en esa red. Estas estrategias aproximaron a los profesionales de la salud y la educación promoviendo el análisis de las implicaciones que mantenían con las instituciones presentes y permitieron que los profesionales de la escuela pusieran sus prácticas en análisis, produciendo así los cambios necesarios.

Palabras clave: política nacional de educación especial; medicalización escolar; salud y educación.

\section{A SAÚDE NA ESCOLA: ALTERNATIVA PARA VELHOS PROBLEMAS OU AMPLIAÇÃO DAS FORMAS DE CONTTRLE?}

Ufa! Bate o sinal, é hora do recreio e O Menino sai correndo, parece desejoso por este momento. Da janela da sala de professores é possivel ver O Menino jogando futebol nos entulhos daquilo que já foi uma quadra, um dia. Alguém lá de dentro retruca: "Pra isso ele serve... Só quer saber de bola ... matemática, que é bom, O Menino quer saber não!”

Uma pequena história, uma cena cotidiana de um/a professor/a cansado/a, uma escola às ruínas, um menino que quer ser criança, uma sociedade que impõe cada vez mais padrões, um sistema que hierarquiza saberes em função do mercado.

E aí está a escola, ela existe, ela resiste! Velhos problemas se atualizam, os modos de engendrar essa roda viva vão assumindo contornos outros e o corpo d'O Menino se molda, para que quando não for mais tão menino assim, continue movimentando a maquínica forma de viver.

Parece uma situação corriqueira, cotidiana, só mais um dia de escola... É isso que interessa aqui. Que lógicas constituem essa forma de organizar o homem moderno? Que lógicas colocam a escola nesse lugar? Como as políticas de educação produzem verdades? Que saberes estão circulando na escola e o que eles produzem? Ao lançarmos estas indagações, não significa que nos colocamos no lugar de respondê-las. Nosso interesse passa pelo modo como se naturalizaram os temas para os quais apontam essas questões. Para tanto, seguiremos apoiados 
nos estudos de Michel Foucault, a fim de pensarmos as lógicas que organizam, sustentam e dão forma a determinadas práticas discursivas e práticas não-discursivas ${ }^{1}$.

O objetivo deste artigo é analisar os efeitos da implementação da Política Nacional de Educação Especial de 2008 (PNEE 2008) nas práticas pedagógicas no município de Linhares, ES, a partir da aproximação entre profissionais da educação e da saúde. Os dados dessa pesquisa são referentes ao ano de 2010, momento em que este município organizou sua rede de educação especial, frente às mudanças exigidas pela política.

Para pensarmos essa configuração no município capixaba vamos recorrer brevemente à história da aliança entre a saúde e a educação e discutir como os saberes ligados à infância psiquiatria, psicologia e pedagogia - e as novas especialidades em saúde - terapia ocupacional e fonoaudiologia - apoiaram-se permitindo a ampliação e o fortalecimento de seus discursos normalizadores, contribuindo para a formação do campo da educação especial.

\section{SAÚDE E EDUCAÇÃO: ENGENDRAMENTOS}

Para seguirmos na análise sobre os efeitos da aliança entre saúde e educação nos apoiaremos nos estudos de Michel Foucault sobre a governamentalidade. Nesses estudos o autor analisa a formação do estado moderno e os modos de subjetivação que operam para melhor atender as demandas do Estado, por meio de técnicas de controle, de normalização, de condução de condutas. Com base na noção de governamentalidade, percebemos como o Estado contemporâneo organiza instituições, procedimentos, cálculos e táticas capazes de conduzir os sujeitos, regulando os modos de vida da população (FOUCAULT, 2009). Quando Foucault formula o conceito de governamentalidade, pretende mostrar a insuficiência das análises sobre o poder, restritas a hierarquias concentradas no Estado. Para além disso, ele quer chamar atenção para o poder que está difuso em nossas práticas, circulando por entre as relações que estabelecemos.

Nessa direção o filósofo elabora este conceito para se referir ao conjunto de técnicas de implementação da ação administrativa, de governo da população, que consistem em reger a conduta dos homens por meio de diversos instrumentos que estão difusos nas diferentes esferas da vida. Trata-se de um conceito importante para pensarmos a educação e a saúde e como a escolarização tem sido uma das bases de sustentação do estado moderno (AQUINO, 2017) que se fortaleceu aproximando esses dois campos.

Por meio da materialização da escola como dispositivo de proteção social do estado liberal, encarregada de levar adiante a normalização das condutas, os sujeitos são expostos a uma série de regulamentos e normas, e enquadrados no discurso da universalização dos direitos. Isso

\footnotetext{
${ }^{1}$ Para Foucault os discursos são muito mais que signos que remetem a conteúdos, os discursos formam os objetos de que falam. Desse modo, uma prática discursiva não trata somente de um ato de fala, mas de ações concretas no ato do discurso. Por meio dessas práticas discursivas constituímos o mundo e nossas relações com ele.
} 
produz ações e significações racionalizadas pelas políticas públicas, capazes de ordenar modos de vida, conformar verdades, produzir e naturalizar modos de existir. Nesse campo de forças, o corpo do sujeito torna-se central, sendo possível imprimir-lhe marcas, afirmar normas que prescrevem suas condutas e, a partir disso, classificá-lo e categorizá-lo. Tal enquadramento permite que esse corpo seja controlado e regulado mediante estatísticas, políticas, direitos, capazes de produzir subjetividades atravessadas por prescrições de condutas e fixação de identidades.

Quando se fixa a normalidade, produz-se a anormalidade; ter a norma como regra de conduta cria a necessidade de corrigir a suposta anormalidade. A relação entre o normal e o anormal é de mútua dependência. No intuito de corrigir, adaptar, reabilitar, ou seja, trazer a anormalidade para o mais próximo da norma, são criados uma série de mecanismos disciplinares, campos de saberes e instituições, como forma de controle e de disciplinarização.

Nesse sentido, o corpo torna-se alvo de ações corretivas e, se possível, preventivas, afinal é preciso regular, padronizar e esquadrinhar esse corpo, pois é ele que produz a força de trabalho, a força que é vendida, que constitui materialidade e faz o sistema funcionar. Em um rápido lance de olhar sobre o corpo que não se enquadra, é possível identificar o desvio da norma. E, ao identificá-lo, é preciso corrigi-lo, recategorizá-lo e fixá-lo em outro lugar. Essa lógica não permite o desvio.

O imbricamento de forças descrito permite a aproximação desses campos - saúde e educação. O campo da medicina e seus especialismos aliados à educação ganham a força necessária para controlar os corpos. Assim, os discursos dos especialistas penetram nas práticas pedagógicas, nos dispositivos institucionais, na escola, modulando as formas de agir e produzindo verdades e subjetividades.

\section{SAÚDE E EDUCAÇÃO: ALIANÇAS}

Tal lógica de ordenamento do corpo favorece a articulação entre os campos da saúde e da educação, que, como vimos, são campos estabelecidos historicamente em torno dos parâmetros de normalidade x anormalidade. Suas práticas consistem, na maioria dos casos, em adequar, prevenir, reestabelecer, reabilitar, readaptar níveis de funcionalidade, sejam eles, comportamentais, cognitivos ou físicos, sempre balizados por parâmetros de normalidade.

A medicina, na modalidade da psiquiatria infantil, ao se aproximar da educação, organizou-se para aperfeiçoar seus instrumentos e promover a adaptação das crianças 'anormais' o mais precocemente possível, tanto no tratamento adequado, quanto na identificação de possíveis atrasos no desenvolvimento.

Como cenário ideal para promover o controle desses corpos infantis, a escola se transforma em um importante lugar para o refinamento das condutas desenhadas pela psiquiatria. Instituído um padrão de desenvolvimento normal e delimitada a ideia do que se pode chamar de atraso no desenvolvimento infantil, é criada a demanda por adaptação das crianças que sofrem 
desse atraso. E, mais que isso, a necessidade em garantir precocemente a identificação de quaisquer atrasos.

Nesse contexto está formada a aliança entre saúde e educação, como campos que se fortalecem por meio de práticas discursivas e não discursivas, capazes de definir tanto na esfera clínica quanto na pedagógica o que se pode chamar de normal e anormal no desenvolvimento da criança e, desse modo, legitimar determinadas práticas.

É possível perceber a aproximação desses dois campos no Brasil já em 1903. Com a implementação da Política Nacional de Educação Especial, nosso país seguiu o debate europeu do início do século XX, estabelecendo as diferenças entre a loucura, a mendicidade e a idiotia e as diferentes abordagens em cada um desses estados. Nesse debate destaca-se o conceito de idiotia, que, diferente do conceito de loucura, é caracterizado pelo atraso no desenvolvimento intelectual. Marcadas essas diferenças, é dada ênfase à irreversibilidade desse quadro clínico e, por isso, entende-se a necessidade de um acompanhamento contínuo, tornando-se, então, demanda para atendimentos nas instituições médico-pedagógicas (LOBO, 2018).

Chama a atenção que, na implementação da PNEE 2008 no município pesquisado, pudemos constatar um desenho parecido, no que concerne ao público-alvo a ser atendido, ao do início do século XX. Em Linhares, no momento da pesquisa, as ações eram prioritariamente organizadas em torno de atendimentos voltados para pessoas com atraso no desenvolvimento intelectual, ainda que a PNEE 2008 preconizasse em seu texto atendimentos às pessoas com transtornos globais do desenvolvimento e altas habilidades/superdotação. Afirmamos isso frente às poucas ações voltadas para crianças com transtornos psiquiátricos, como esquizofrenia infantil, por exemplo, tendo em vista que tais ações eram consideradas demandas para a política de saúde mental e seus atendimentos realizados nos Centros de Atenção psicossocial infantil (Capsi), serviço que até o momento da pesquisa não existia naquele município. Diante desse cenário, havia dificuldade de os serviços que atendiam crianças encaminharem e acolherem essas crianças e adolescentes nos serviços disponíveis na rede.

Ainda em 1903 foram criadas estratégias que visavam à promoção da higiene médicopedagógica das crianças acometidas pelo atraso no desenvolvimento. Dentre estas ações e serviços foram criados o Pavilhão-Escola Bourneville no Hospício Nacional, no Rio de Janeiro; a inspeção médico-escolar no Rio de Janeiro e em São Paulo, e junto a estes serviços, a disseminação de protocolos, avaliações e saberes psiquiátricos no interior das escolas; e como efeito dessa disseminação, a demanda pela criação de novos serviços e especialidades voltadas ao atendimento de crianças com possíveis atrasos no desenvolvimento (LOBO, 2018). Como destaca a autora, esse trabalho tornou-se tão efetivo que nesse período foi registrado um aumento significativo no número de crianças internadas no Pavilhão-Escola Bourneville.

É interessante notar que esse aumento de demanda por dispositivos de educação especial também foi um movimento observado após a aproximação entre saúde e educação no município onde essa pesquisa foi desenvolvida, efeito que será tomado como analisador e será debatido adiante. 
DOI: $10.12957 /$ teias.\%Y.50845

A educação especial, como área da educação que surge dessa aproximação com a saúde, organiza suas práticas a partir da categorização e separação dos indivíduos com base nos padrões de normalidade. Nesse sentido, é preciso problematizar suas práticas e colocar em questão seus instrumentos, posto que, sob o discurso da qualidade de vida, se organizam em função da normalização dos sujeitos.

\section{MEDICALIZAÇÃO SOCIAL}

Diversos pesquisadores (PATTO, 1999; MACHADO, 2004; MOYSÉS E COLLARES, 2006; GUARIDO, 2007; CALIMAN E FIGUEIRA, 2014) têm debatido a medicalização social, um fenômeno descrito como a tendência a biologizar as questões sociais e a transformar questões coletivas em problemas individuais e muitas vezes bio-psico-patológicos. Esta lógica tem sido naturalizada nas práticas cotidianas, extrapolando a área da educação especial e constituindo um modo de funcionamento da escola (MACHADO, 2004).

A medicalização social é um fenômeno que avançou junto às transformações da medicina e se desenvolveu com este próprio campo enquanto ele conquistava seu estatuto de ciência. Este foi o primeiro campo da ciência que tomou por objeto os seres humanos e assim, constituiu a raiz epistemológica das ciências do homem. A medicina científica, que se desenvolveu por meio do método clínico, tomou para si o conhecimento sobre o corpo em todas as suas formas. De um lado, ela se apropria do corpo doente, pelo qual passa a ser possível produzir um discurso sobre o que é visto. A doença passa a se legitimar pela linguagem e pelo olhar. A medicina nos fornece as lentes para se fazer ver, ela se torna capaz de trazer à visão o invisível (MOYSÉS E COLLARES, 2006).

Por outro lado, o corpo saudável, deve ser cuidado, regulado por meio da ciência que prescreve o que deve ser feito, que diz como conduzir esse corpo, seus padrões de ser/estar saudável, controlados por um minucioso controle populacional e territorial. Como destaca Foucault em suas análises sobre o biopoder, estamos inseridos em um conjunto de mecanismos que tem na vida biológica e seus processos, um campo fundamental de atuação.

Com o conceito de biopoder, Foucault chama a atenção para a crescente ampliação dos saberes biológicos e biomédicos, dispositivos jurídicos-institucionais que estão articulados tanto em nossas relações com o Estado, quanto em nossos modos de vida. A partir desse campo analítico, fica mais facilmente compreensível a articulação entre a saúde e a educação e como a medicalização social, efeito dessa aliança, tem penetrado nos dispositivos sociais. Com a inserção do conceito de biopoder/biopolítica, as análises foucaultianas seguiram na direção do que ele chama de novas formas de exercício de poder, em que ele percorre as técnicas que se destinam ao controle da própria espécie. A população é o conceito que emerge para dar conta do controle coletivo, múltiplo, descritível e numerável (FOUCAULT, 2009).

O que nos interessa nesse diálogo com os conceitos foucaultianos é trazer a reflexão sobre como diferentes técnicas que fazem parte do nosso cotidiano precisam ser analisadas como técnicas difusas, manifestadas nas instituições e nas práticas capazes de conduzir as condutas. Ao 
DOI: $10.12957 /$ teias. $\%$ Y.50845

desenvolver a noção de governamentalidade, Foucault chama a atenção para a racionalidade das práticas de controle, vigilância governamental das populações, além de discutir as práticas de governamentalidade liberal em sua racionalidade própria de "estratégia sem estrategista".

Nessa governamentalidade a medicina tem um importante papel, pois é capaz de produzir verdades e legitimar práticas. Ao tomar para si a legitimidade de categorizar os modos de existir, ela produz a medicalização da vida. Quando a ciência médica se acopla a outras ciências dos mais diferentes campos, penetra em diferentes dispositivos institucionais, atravessa diferentes práticas e permite a modulação dos discursos a partir da variável saúde-doença. No momento que essa variável penetra nas práticas e discursos, uma série de deslocamentos são produzidos e abre-se uma fenda para que as demandas sociais sejam esvaziadas de sentido.

Essa fenda permite a emergência do fenômeno da medicalização social, à medida que as questões sociais são deslocadas para a esfera individual e que se reduzem ao corpo do sujeito questões que precisam ser debatidas na esfera coletiva. Para individualizar tais questões, são construídas explicações organicistas como respostas para as dificuldades enfrentadas, por exemplo, pela escola. Um dos efeitos desses deslocamentos é o esvaziamento do debate político. Desse modo, quando as questões sociais ficam substancializadas e reduzidas à variável saúdedoença, em que tudo se explica a partir das relações do corpo biológico, isso certamente terá como efeito a camuflagem dos engendramentos que conduzem a vida social (MOYSÉS E COLLARES, 2006).

\section{METODOLOGIA}

Por meio dos deslocamentos do nível coletivo para o individual, a medicalização social toma forma no espaço escolar, deslocando também as responsabilidades. Nesse sentido, diante do objetivo de analisar os efeitos da implementação da Política Nacional de Educação Especial de 2008, no município de Linhares, ES, sobre as práticas pedagógicas, a partir da aproximação entre a educação e uma equipe de saúde, seguimos nossas análises a partir dos referenciais teóricos da análise institucional (AI).

Vale ressaltar que as práticas descritas e analisadas neste artigo resultaram do estranhamento daquela equipe de trabalho com práticas instituintes que começaram a se movimentar a partir da aproximação entre a saúde e a educação na escola. Foi a partir desse estranhamento que a equipe empreendeu suas críticas e buscou analisar coletivamente o trabalho realizado, assim como buscou estratégias que pudessem diminuir os efeitos do processo de medicalização que estava se instituindo. Desse modo, retornamos àquela experiência, agora sob as lentes da AI, entendendo que a AI nos permite olhar para a história, olhar para as instituições e fazer uma apreciação retrospectiva dos fatos, a fim de colocar em análise as atuais práticas sedimentadas, bem como problematizar os deslocamentos possíveis.

Logo após a mudança da política e da organização da rede resultante da aproximação formalizada entre a saúde e a educação, um dos efeitos percebidos foi o aumento da demanda de avaliação das dificuldades de aprendizagem e dificuldades comportamentais dos estudantes, por 
DOI: $10.12957 /$ teias.\%Y.50845

parte das escolas e de seus profissionais. Este efeito se configurou como um analisador histórico ${ }^{2}$ : Aumento da demanda por avaliação, entendendo-se que por meio desse analisador pudemos questionar os múltiplos sentidos cristalizados na instituição saúde e, em particular na articulação desta com a educação, que operavam legitimando práticas na escola por meio de discursos instituídos, sobretudo quando esses discursos eram produzidos no interior de um campo de saber hegemônico como é a saúde e suas especialidades.

Neste percurso, ao apresentarmos a demanda de encaminhamentos realizados pelos professores para avaliação do serviço de saúde, muito mais do que identificar esses processos de produção e seus condicionantes, nos colocamos a pensar sobre os efeitos destas práticas e a questionar os fenômenos políticos, econômicos e sociais que têm levado profissionais da saúde e da educação a identificarem sintomas patológicos nas crianças em idade escolar.

\section{DE QUE LUGAR ESTAMOS FALANDO?}

O ponto de partida para as reflexões trazidas neste estudo se dá a partir da implementação da Política Nacional de Educação Especial, na perspectiva da educação inclusiva de 2008 no município de Linhares, ES. Vale ressaltar que essa política traz como objetivo "[...] orientar os sistemas de ensino para garantir: acesso ao ensino regular, com participação, aprendizagem e continuidade nos níveis mais elevados do ensino; transversalidade da modalidade de educação especial desde a educação infantil até a educação superior" (BRASIL, 2008; p. 11).

Ela ainda define quem são os alunos atendidos por essa rede (alunos com deficiência, com transtornos globais do desenvolvimento e altas habilidades/superdotação) e estabelece os serviços complementares que deverão ser oferecidos aos alunos público-alvo desta política: “[...] oferta do atendimento educacional especializado; formação de professores para o atendimento educacional especializado e demais profissionais da educação para a inclusão; acessibilidade arquitetônica, nos transportes, nos mobiliários, nas comunicações e informação" (BRASIL, 2008; p.11). Ainda no final do parágrafo, que expõe os objetivos e o público-alvo, o texto enfatiza a necessidade de uma articulação intersetorial para sua efetivação.

Nos anos seguintes ao lançamento da PNEE 2008, no Estado do Espírito Santo, a Secretaria Estadual de Educação (SEDU), em convênio com a Universidade Federal do Espírito Santo (UFES), iniciou o processo de implementação da política nos municípios capixabas. Dentre algumas ações, destacamos a elaboração das diretrizes da educação especial na educação básica e profissional da rede estadual de ensino e o curso de formação de gestores da educação especial.

\footnotetext{
2 Analisadores históricos e construídos: para a Análise Institucional, o analisador pode ser histórico, ou seja, fatos ou acontecimentos gerados pela/na própria vida histórica-social-natural ou construído, quer dizer, os dispositivos, os procedimentos ou quaisquer outros recursos inventados pelos analistas institucionais e utilizados na situação de intervenção.
} 
DOI: $10.12957 /$ teias. $\%$ Y.50845

Impulsionados por esse movimento, nesse período foram feitas ações em nível estadual e municipal que articularam a implantação das salas de recursos multifuncionais e a formação de professores para oferecerem o atendimento educacional especializado (AEE).

Essa mobilização chega ao município de Linhares por meio de profissionais da educação, que atuavam na Associação Pestalozzi de Linhares ${ }^{3}$, nas secretarias municipal e estadual de educação, e acompanharam a formação feita pela UFES

Ao longo dos anos, a Pestalozzi desenvolveu um trabalho de parceria com a rede pública de ensino, no âmbito da educação especial, por isso sua atuação foi central no processo de implementação da política no município. A primeira ação importante da Pestalozzi foi sua adequação à política, deixando de atender como escola especial para atender como "Centro de Atendimento Educacional Especializado" (CAEE).

Com isso, a instituição reestruturou todo seu projeto político pedagógico para atender à modalidade da educação especial na perspectiva da educação inclusiva. Com essa nova configuração, o CAEE iniciou o processo de inclusão dos alunos na rede regular de ensino e passou a oferecer o AEE como complementar, seguindo a proposta das salas de recursos multifuncionais.

Como o CAEE foi central nessa articulação, seguindo a recomendação da própria política no que tange à necessidade de articulação intersetorial, foi montada nesse centro uma equipe de saúde para ser referência na avaliação dos alunos de toda a rede pública do município, que na época era composta de aproximadamente 75 escolas e centros municipais de educação infantil e 45 escolas estaduais de ensino médio.

A equipe que tinha a função de fazer as avaliações era composta por um terapeuta ocupacional, uma psicóloga, uma fonoaudióloga, um neurologista e uma psicopedagoga. $\mathrm{O}$ trabalho dessa equipe era receber estudantes da rede regular de ensino (infantil, fundamental, médio, EJA) que haviam sido identificados pela equipe da escola como "portadores de problemas", fosse pela questão da aprendizagem, fosse pela questão do comportamento.

Tratava-se de um processo de trabalho definido pela gestão da instituição e pela gestão municipal da educação especial, anteriormente à composição da equipe. $O$ trabalho consistia em

\footnotetext{
3 A Associação Pestalozzi de Linhares foi fundada em 22 de junho de 1984. Foi criada com o objetivo de promover e articular ações de defesa de direitos, prevenção, orientação, prestação de serviços, apoio à família, direcionadas à melhoria da qualidade de vida da Pessoa com Deficiência. De acordo com o artigo $1^{\circ}$ de seu estatuto, a Associação Pestalozzi de Linhares tem por fins o estudo, a assistência, o tratamento e a educação de crianças, adolescentes e adultos que necessitam de assistência psicopedagógica, médica, odontológica e de reabilitação. As atividades da Instituição são financiadas por doações ou contribuições voluntárias, através de convênios firmados com o Ministério da Assistência Social, com a Prefeitura Municipal de Linhares, com a Prefeitura Municipal de Sooretama, com o Fundo para Infância e Adolescência, com a Secretaria de Assistência Social e Direitos Humanos e com a SEDU. A Associação Pestalozzi de Linhares é uma entidade inteiramente voltada para prestação de serviços em Educação Especial, contribuindo para melhorar a qualidade de vida da pessoa com deficiência ou transtorno global do desenvolvimento, promovendo sua inclusão social, não possuindo fins lucrativos. Disponível em http://pestalozzilinhares.com.br/. Acesso em 13 set. 2015.
} 
DOI: $10.12957 /$ teias. $\%$ Y.50845

avaliar esses sujeitos, orientar a família e, a partir das observações da equipe, eram feitos os encaminhamentos para o atendimento educacional especializado e para o atendimento clínico ambulatorial, caso se considerasse tal necessidade.

Vale ressaltar que esse modelo de trabalho era bastante questionado pelas profissionais, que reivindicavam a necessidade de se abrir um espaço de diálogo e discussão entre a equipe de saúde e os profissionais da escola, mas essa prática era vista como inviável pela equipe gestora, devido ao financiamento reduzido para a contratação de mais profissionais.

Em poucos meses de funcionamento com essa configuração, ocorreu o aumento da demanda de trabalho, passando de uma média de dez atendimentos semanais em 2009, para uma média de 40 atendimentos a estudantes em 2010, números que demonstram como a atuação teve efeito direto no funcionamento das escolas. Como exemplo, questões que até então estavam presentes no cotidiano da escola, tais como estudantes com menor interesse pelos estudos ou estudante que apontava muitas vezes o lápis (informação descrita em um relatório emitido pela escola) passaram a ser entendidas como problemas, resultando no encaminhamento desses e de outros casos para serem avaliados pela equipe de saúde.

Essas mudanças observadas na escola e a crescente demanda por avaliação provocaram o estranhamento daquelas profissionais da equipe de saúde. Com o objetivo de questionar as forças presentes naquela rede de educação, elas levaram esse debate a diferentes espaços com o intuito de mobilizar os diversos atores da rede - professores, gestores, pedagogas, mediadores, etc. - a problematizarem as práticas e também as estratégias possíveis para criarem outros modos de existir.

\section{O QUE FAZ MOVIMENTAR A SAÚDE NA EDUCAÇÃO?}

A problematização dos efeitos da implementação de políticas públicas nas práticas cotidianas dos profissionais da educação e as estratégias utilizadas em tal processo vão ao encontro daquilo que entendemos como fundamental no âmbito das discussões sobre políticas públicas. Ao transitarmos por suas racionalidades, buscamos desnaturalizar as verdades construídas em torno do lugar que essas políticas ocupam, além de desmistificar o discurso de neutralidade.

As práticas produzidas com a implementação da PNEE 2008 em Linhares, observadas a partir de relatórios e pareceres emitidos por profissionais da saúde e da educação, apontam para a penetração do fenômeno da medicalização na escola. Utilizando-se de explicações organicistas e recursos técnicos do campo da medicina para explicar questões ligadas à aprendizagem e ao comportamento dos sujeitos, o discurso medicalizante tem ganhado força no âmbito da escola e camuflado os tensionamentos próprios da convivência escolar.

É inegável que a implementação da PNEE 2008 trouxe avanços significativos ao campo da educação especial. Contudo, a forma como o município aqui analisado implementou a política também permitiu a penetração dos discursos dos especialistas da saúde na educação, o que, 
consequentemente, fez operar nas escolas daquela rede um modo medicalizante de conduzir suas práticas e resolver seus conflitos.

Heckert e Rocha $(2012$, p. 88, 90) chamam a atenção para a dificuldade dos profissionais da educação em lidar com determinadas práticas contemporâneas, produzindo aumento no número de encaminhamentos de estudantes para neurologistas e psiquiatras. De acordo com as análises desenvolvidas por essas autoras, essa dificuldade pode ter relação direta, por exemplo, com a composição da rede de educação especial, que tem no centro de suas ações o serviço de saúde. A corroborar com essas análises está a maneira como o processo de encaminhamento dos estudantes até a avaliação era conduzida em Linhares, por muitas vezes, sem que a escola tivesse uma discussão coletiva prévia dos casos nem tentativas internas coletivizadas de resolver as dificuldades.

Essa prática de ter uma equipe de profissionais da saúde como principal responsável pela porta de entrada dos alunos nos equipamentos de atendimento educacional especializado reforça a "[...] crença que o diagnóstico fornecerá subsídios para a intervenção pedagógica, com vistas a superar as dificuldades do aprender" (HECKERT E ROCHA, 2012, p.90). Como efeito dessa prática, o que assistimos ser produzido foi o encaminhamento dos alunos para atendimento fora da escola, em vez de fortalecer a inclusão da diversidade no âmbito escolar.

Além disso, essa organização do modo de trabalhar produziu o esvaziamento da potência dos profissionais da escola na busca por estratégias de trabalho e alternativas para lidar com as dificuldades dos alunos. O fato de os encaminhamentos passarem a ser corriqueiros e naturalizados demonstra certo silenciamento daqueles profissionais frente aos discursos de um saber hegemônico, como os da saúde e seus especialismos. Ao assumirem e validarem os discursos e práticas medicalizantes, os profissionais da educação reforçam o lugar de hegemonia da saúde, afastando deles próprios as responsabilidades sobre o fracasso dos estudantes.

Vale notar que essa postura esvazia os espaços possíveis de se constituir uma relação de ensino-aprendizagem criativa e que possa resultar em transformações, como nos chama atenção, Guarido e Voltolini (2009, p. 255):
A sujeição ao corpo orgânico reduz em muito as possibilidades de pensarmos nas dimensões simbólicas das relações educativas entre adultos e crianças. Assim, mais uma vez há uma tendência ao esvaziamento do ato educativo e da densidade da experiência humana.

No contexto geral dessa rede de educação, o aumento da demanda pelos serviços de saúde ganhou força, produziu práticas e discursos. Laudos e pareceres foram tomando lugar de práticas inventivas no interior da escola, o fazer infantil foi esvaziado pela lógica medicalizante e a escola foi ficando com poucas brechas para experimentações.

Como já apontado, vale ressaltar que o modelo de trabalho da equipe de saúde era bastante questionado pela terapeuta ocupacional, pela fonoaudióloga, pela psicóloga e pela psicopedagoga daquela equipe, que reivindicavam a necessidade de se abrir um espaço de diálogo e discussão entre a equipe de saúde e os profissionais da escola. Como já foi dito, essa prática era 
vista como inviável pela equipe gestora. Frente às dificuldades, essas trabalhadoras foram criando suas próprias estratégias. A primeira delas foi ampliar o espaço de debate entre elas próprias, colocando constantemente em análise suas práticas e os fatores que contribuíam para que a alta demanda fosse produzida. Desses espaços surgiram algumas estratégias, como a criação de um relatório feito pela equipe após a avaliação.

Nesses relatórios, a equipe apresentava uma descrição geral da demanda da escola e da família, além de comentários voltados para as potências observadas no estudante. Evitava-se, portanto, focar nas queixas ou nas supostas deficiências. Por fim, eram feitas orientações sobre como a escola poderia criar suas próprias estratégias para lidar com os estudantes. É importante destacar que eram raros os casos que chegavam à equipe de saúde com uma real demanda de dificuldade cognitiva ou psíquica. Os casos, em sua grande maioria, estavam ligados às questões de comportamento. Entretanto, nos casos que a equipe identificava que o estudante tinha demandas para atendimento ali, os encaminhamentos eram dados diretamente à família e os relatórios se direcionavam nesse mesmo sentido. Outra estratégia utilizada era entregar os relatórios por intermédio das chamadas professores itinerantes, profissionais 'especialistas em educação especial', que conseguiam de alguma forma promover a escuta dos profissionais da escola e, mesmo sem aprofundarem questões, pensavam juntos com eles em formas de lidar com suas dificuldades, evitando-se a intervenção da saúde.

Além disso, essas profissionais da saúde passaram a frequentar as reuniões e fóruns promovidos pelo setor de educação especial e juntos ampliavam os sentidos das dificuldades vividas pela escola. Tentando deslocar as análises, antes centradas no corpo do aluno, como se todos os problemas tivessem um cunho biológico ou psicológico, elas buscavam problematizar os espaços cotidianos, espaços onde as instituições sociais se atualizam.

O grupo ainda conseguiu ampliar os âmbitos de discussão por meio da participação da terapeuta ocupacional e de duas fonoaudiólogas nos cursos de formação em educação especial para os professores da rede. A ementa desses cursos era permeada pelas problematizações em torno da produção do fracasso escolar e da medicalização social; os professores cursistas traziam suas questões para análise coletiva e a partir disso se davam os debates. Nesse período muitos professores expressaram mudanças em suas práticas e em suas formas de entender o cotidiano da escola. Em dois anos foram aproximadamente 250 professores formados por esses cursos.

Além disso, foi possível notar que a partir das discussões entre os profissionais de saúde, o olhar daquela equipe também se deslocou na abordagem com as famílias. No início do trabalho, havia uma tendência muito forte de culpabilização da família, como se as dificuldades apresentadas pelos estudantes fossem resultantes da negligência familiar. Um tipo de pensamento presente na formação dos profissionais de saúde e educação que está diretamente ligado à noção de norma, a partir da qual qualquer "anormalidade" observada pelo especialista se transforma em cobrança e até em punição desses pais, por não cumprirem as normas da saúde, nesse caso, articuladas à educação (LEMOS, 2014).

Como podemos ver, as práticas de análise coletiva instrumentalizadas pela equipe produziram uma série de deslocamentos na própria prática dessas profissionais e nos modos 
DOI: $10.12957 /$ teias.\%Y.50845

como essa equipe chegava à escola. Por mais que não fossem operadas grandes mudanças na estrutura da secretaria de educação, acreditamos que as forças que operaram na micropolítica foram capazes de deslocar o campo da experiência dos sujeitos por meio da transformação do campo da existência.

Neste artigo, a análise foi realizada com as lentes da AI, isso significa que tomamos essa pesquisa como forma de questionar os múltiplos sentidos cristalizados nas instituições, entendendo que a AI tem a capacidade de afirmar um lugar desarticulador das práticas e dos discursos instituídos. Também nessa direção analisamos os deslocamentos operados naquela equipe, que por meio da análise coletiva conseguiu operar mudanças em suas práticas, questionando inclusive os discursos produzidos como científicos.

Esse lugar da saúde como hierarquicamente superior aos demais campos de saber era bem marcado na organização da rede de educação especial daquele município. Eram frequentes as situações que as profissionais de saúde eram convocadas a darem respostas às situações do cotidiano da escola, mesmo que muito distantes daquelas múltiplas realidades.

Mais uma vez, com as ferramentas da AI foi possível para esta equipe colocar em análise os instituídos e deslocar as barreiras hierárquicas produzidas pelas divisões de especialidades, responsáveis em fragmentar o cotidiano e isolar os profissionais (AGUIAR \& ROCHA, 2003, p. 71). Em determinadas situações, por exemplo, a equipe assumia que não tinha respostas e tentava de várias maneiras possíveis a aproximação com os profissionais da escola, a fim de pensarem sobre as práticas, em vez de emitirem relatórios prescritivos sobre como fazer - ainda que, muitas vezes, fosse essa a postura que o grupo gestor da educação especial, os professores e os familiares esperavam dela.

\section{CONSIDERAÇÕES FINAIS}

No âmbito de nossas análises, a implementação de uma política sem um diálogo com os profissionais envolvidos e as experiências cotidianas pode ter como efeito, como pudemos constatar em Linhares, a despotencialização destes profissionais - os da educação - que identificam seu saber como um saber menor, frente ao saber médico, hegemônico e naturalizado como verdadeiro. A insatisfação dos profissionais de saúde diante do modelo de trabalho estabelecido e a busca para tornar o trabalho mais efetivo apontaram para a necessidade de olhar para as políticas no interior dos dispositivos.

A possibilidade de nos aproximarmos das demandas dos professores denunciou o distanciamento entre os textos da lei e o cotidiano da escola e colocou em análise os modos como a arte liberal de governar, por meio de seus regulamentos e normas, controla e assujeita as formas de vida.

Os relatórios emitidos pelos professores quando encaminhavam seus alunos para avaliação apontavam ainda para outros efeitos da aproximação entre saúde e educação. Neste artigo, nos limitamos a analisar a alta demanda produzida desde a constituição da equipe de saúde. Entendemos que a produção dessa demanda também estava ligada à forma medicalizante 
que atravessava as práticas dos profissionais de saúde, especialmente quando convertiam problemas de aprendizagem em problemas de ordem biológica e psíquica, o que consequentemente reforçava a penetração dos discursos médicos na escola, produzindo práticas e discursos que afastavam os aspectos sociais das discussões em torno desses problemas.

Com isso, a implementação da PNEE no município de Linhares, ES, situando as profissionais de saúde no centro do processo, produziu como efeito uma demanda bem específica: o atendimento educacional especializado e o atendimento clínico ambulatorial. Esperava-se que o atendimento oferecido por essas profissionais solucionasse as dificuldades produzidas na escola. Isso aponta para uma série de práticas e discursos que, a partir da constituição desses serviço,s passaram a dar contorno ao funcionamento da escola, ou seja, toda essa engrenagem de 'especialistas e serviços especializados' passou a fornecer lentes para a escola, dizendo "[...] o que se vê e também fazendo ver", situação esperada pela própria constituição da medicina e seu método clínico. Segundo Moysés e Collares (2006, p. 161),

$\mathrm{Na}$ articulação entre linguagem, espaço e morte, constitui-se o método clínico. Desde seus primórdios, a medicina traz em si a busca de uma linguagem que possibilite a equivalência absoluta entre o visível e o enunciável, entre o significado (a doença) e o significante (o sintoma); uma equivalência absoluta porque sem resíduos. A linguagem constitui ponto central na construção do método clínico: dizer o que se vê, mas também, fazer ver, dizendo o que se vê. Sob uma linguagem aparentemente superficial, presa a descrever o visível, revela-se na linguagem médica, o ato de desvelamento. Desvelamento do interior, tornando legível o invisível. A medicina moderna se constitui na coexistência e disputa entre concepções distintas sobre doença. Reajustes do olhar, mudanças de foco, de local, representam mudanças conceituais importantes, porém jamais cortes epistemológicos.

Nesse período, observou-se que questões até então corriqueiras no cotidiano escolar como a dispersão da atenção, a agitação, o questionamento, a inquietação ou, ao contrário, o comportamento muito quieto - tornaram-se potenciais disfunções neuropsicológicas dos estudantes e, portanto, produziram demanda para a avaliação por parte de uma equipe de saúde.

Por outro lado, frente ao aumento da demanda por avaliação, a equipe de saúde teve um posicionamento bastante crítico, produzindo potentes debates acerca de suas práticas, sobre os instituídos e, sobretudo, acerca das práticas instituintes que estavam sendo mobilizadas no cotidiano das escolas e que se direcionavam para o aumento desenfreado da medicalização escolar. A título de exemplo, citamos a exigência de laudo médico para o Atendimento Educacional Especializado.

Diante disso, a equipe foi capaz de produzir estratégias para minimizar os efeitos da medicalização escolar naquela rede, oferecendo outras lentes para olhar o cotidiano da escola, a partir dos debates feitos nas reuniões de professores e nos cursos de formação em educação especial. 
DOI: $10.12957 /$ teias. $\%$ Y.50845

Mais que isso, as estratégias e as discussões desenvolvidas a partir da aproximação entre os profissionais dos dois campos - saúde e educação -, com base, então, num enfoque diferenciado, que recusava o discurso medicalizante naturalizado, foram fundamentais para que muitos profissionais da escola também pudessem colocar suas práticas em análise e ganharem confiança na capacidade de produzir mudanças na escola.

E sabe aquele Menino, O Menino que só queria saber de bola? Descobriram o porquê! Tão agitado, só podia SER hiperativo mesmo. Hoje...toma duas "Concerta " por dia, e agora, tão calmo e tranquilo, nem precisa mais de bola pra se distrair. E matemática? Não aprende mesmo, tadinho, ele tem problema de atenção.

\section{REFERÊNCIAS}

AGUIAR, Katia Faria; ROCHA, Marisa Lopes da. Pesquisa-intervenção e a produção de novas análises. Psicologia, Ciência e Profissão, Brasília-DF, v. 23, n. 4, p. 64-73, dez. 2003.

AQUINO, Julio Groppa. Defender a escola das Pedagogias Contemporâneas. ETD - Educação Temática Digital, Campinas SP, v. 19, n. 4, p. 669-690, out./dez. 2017. Disponível em https://periodicos.sbu.unicamp.br/ojs/index.php/etd/article/view/8648729/16858. Acesso em 01 jul. 2017.

BRASIL. Ministério da Educação. Politica Nacional da Educaşão Especial na perspectiva da educação inclusiva. 2008. $15 \mathrm{p}$.

CALIMAN, Luciana Vieira; FIGUEIRA Paula Lampé. Considerações sobre os movimentos de medicalização da vida. Psicologia clínica, Rio de Janeiro, v. 26, n. 2, jul./dez. 2014. Disponível em http://www.scielo.br/scielo.php?script=sci arttext\&pid=S0103-56652014000200002. Acesso em 01 jul. 2017.

FOUCAULT, Michel. Segurança, Território e População. São Paulo: Martins Fontes, 2009.

GUARIDO, Renata. A medicalização do sofrimento psíquico: considerações sobre o discurso psiquiátrico e seus efeitos na Educação. Educação e pesquisa, São Paulo, v. 33, n. 1, p. 151-161, jan./abr. 2007. Disponível em http://www.scielo.br/pdf/ep/v33n1/a10v33n1.pdf. Acesso em 25 jul. 2017.

GUARIDO, Renata; VOLTOLINI, Rinaldo. O que não tem remédio, remedido está? Educação em Revista, Belo Horizonte, v. 25, n. 01, p. 239-263, abr. 2009. Disponível em http://www.scielo.br/pdf/edur/v25n1/14.pdf. Acesso em 25 jul. 2017.

HECKERT, Ana Lúcia Coelho; ROCHA, Marisa Lopes da. A maquinaria escolar e os processos de regulamentação da vida. Psicologia e Sociedade, v. 24, n. (spe), p. 85-93. 2012. Disponível em https://www.scielo.br/pdf/psoc/v24nspe/13.pdf. Acesso em 8 mai. 2020.

LEMOS, Flavia Cristina Silveira. A judicialização da infância: seus impactos na vida das crianças e suas famílias. Desidades, Rio de Janeiro, v. 2, n. 2, p. 25-29, mar. 2014. 
DOI: $10.12957 /$ teias.\%Y.50845

LOBO, Lilia Ferreira. Pavilhão Bourneville: esboço de uma história da psiquiatria infantil no Brasil In: LOBO, Lilia Ferreira; FRANCO Débora Augusto (org). Infâncias em Devir: ensaios e pesquisas. Rio de Janeiro: Editora Garamond, 2018. p. 17-29.

MACHADO, Adriana Marcondes. Encaminhar para a saúde quem vai mal na educação: um ciclo vicioso? Revista Educação, SME, São Paulo, 2004.

MOYSÉS, Maria Aparecida Affonso; COLLARES, Cecília Azevedo Lima. Medicalização: elemento de desconstrução dos direitos humanos. In: CRP-RJ (org.). Direitos Humanos: o que temos a ver com isso? Rio de Janeiro: CRP-RJ, 2007. p. 153-168.

PATTO, Maria Helena Souza. A produção do Fracasso Escolar: histórias de submissão e rebeldia. São Paulo: Casa do Psicólogo, 1999.

\section{Informações dos autores}

Roberta de Mendonça Porto

Doutora em Políticas Públicas e Formação Humana (PPFH/UERJ)

E-mail: bethamendonca10@gmail.com

ORCID: https://orcid.org/0000-0002-1370-4328

Link Lattes: http://lattes.cnpq.br/0517903236309594

Luiz Antonio Saléh Amado

Professor Associado FEBF/PPFH/UERJ

E-mail:saleh.amado@gmail.com

ORCID: https://orcid.org/0000-0002-4629-867X

Link Lattes: http://lattes.cnpq.br/9927528393436035 